\title{
COMPORTAMENTO DE NOVAS VARIEDADES HOLANDESAS DE BATATINHA (1)
}

SÉRgIo MonteIro CuRI, engenheiro-agrônomo, Seção de Raizes e Tubérculos, Instituto Agronômico

\section{SINOPSE}

São relatados os resultados de nove ensaios, localizados em cinco regiões produtoras de batatinha do Estado de São Paulo, para estudar o comportamento, como tubérculo-semente, de quinze novas variedades de batatinha (Solanum tuberosum $\mathbf{L}$.) obtidas na Holanda.

As variedades Engelum G 495, Dykhuis 52-211, Emergo, Arka e Multa apresentaram as melhores produções quando plantadas em janeiro-fevereiro e em solo latosol vermelho-amarelo orto ou solo podzolizado com cascalho. As três primeiras variedades citadas também obtiveram as melhores produções em solo podzólico variação Marília. Dalco, Emergo, Plat 52-9 e Engelum G 495 mostraram-se as mais produtivas quando plantadas em outubro-novembro e em solos podzólico vermelho-amarelo variação Laras ou orto.

As variedades Dykhuis 52-211, Humalda, Engelum G 495, Emergo, Arka, Realta e Radosa apresentaram as maiores porcentagens de tubérculos graúdos. Primura, Bintje e Dykhuis 52-211, apresentaram os melhores aspectos de tubérculo.

Kuik 54-22 e Realta apresentaram leve resistência às moléstias requeima e pinta preta, ocasionadas pelos fungos Phytophthora infestans (Mont) de Bary e Alternaria solani, Kuhn. As demais não apresentaram resistência àquelas doenças.

\section{1 - INTRODUÇÃO}

O Instituto Agronômico de Campinas tem recebido há alguns, anos, pelo órgão oficial holandês de batatas-semente, o Instituto

(1) O autor agradece a colaboração prestada, na condução dos ensaios, pelos Eng. us Agr.os Sebastião Alves, Jayme Caner, Nilo Borges de Figueiredo e Hideu Tasaka e agricultores Srs. Kazuisa Ninomyia, Irmãos Hojo, Mário Tonarelli, Kazumi Liatatani, Masao Takahashi e Tadao Murozaki. Recebido para publicação em 15 de setembro de 1966. 
do Estado para Exame de Variedades de Produtos Agricolas, conhecido pela sigla I.V.R.O., lotes de diversas, variedades recém-obtidas de batatinha. O mútuo interêsse destas entidades repousa no intuito de descobrir, sob nossas condiçōes de solo e clima, variedades que venham a superar as já existentes ou que, por apresentarem caracteristicas desejáveis, possam servir aos trabalhos de melhoramento aqui levados a efeito.

Este trabalho refere-se às variedades recebidas nos anos de 1963,1964 e 1965. Nêle relata-se os resultados alcançados por quinze novas variedades, confrontando-as com a variedade Bintje, que ocupa o primeiro lugar na área cultivada no Estado de São Paulo.

\section{2 - MATERIAL E MÉTODO}

Foram as seguintes as variedades estudadas:

Multa

Dykhuis 52-211

Engelum G 495

Kuik 54-22

Emergo (Ex. Geertsema 51-16)

Primura

Plat 52-9

Bintje (testemunha)
Spartaan (Ex. C.I.V. 51-119)

Humalda (Ex. Engelum H 468)

Radosa (Ex. Redemakers 54-103)

Doornbos 52-114

Arka (Ex. Konst 53-212)

Dalco

Realta

Extase

As variedades Loman 43-35, Plat 52-11 e Dekker 51-638, presentes nos ensaios realizados em 1963, foram substituídas nos anos seguintes pelas variedades Multa, Kuik 54-22 e Doornbos 52-114.

Os campos experimentais foram adubados com uma mistura que continha respectivamente 80,120 e 60 quilos, por hectare, de $\mathrm{N}, \mathrm{P}_{2} \mathrm{O}_{5}$ e $\mathrm{K}_{2} \mathrm{O}$.

O delineamento usado foi o de blocos ao acaso com cinco repetições.

\section{3 - RESULTADOS E DISCUSSÃO}

As observaçōes que șe seguem, foram comuns à maioria dos ensaios. Os melhores desenvolvimentos vegetativos couberam às variedades Bintje, Emergo, Arka e Dalco. A variedade Realta apresentou o menor desenvolvimento e lentíssimo crescimento vegetativo. A variedade Engelum G 495 mostrou propensão ao 
enrolamento fisiológico das fôlhas. Os melhores aspectos de tubérculos se deveram à Primura, Bintje, Dykhuis 52-211 e Humalda. Dykhuis 52-211 apresentou tubérculos com polpa de coloração creme; as demais variedades, polpa de coloraçāo amarela. łmergo e Arka apresentaram tubérculos com película avermelhada, e as demais película amarela. Engelum G 495 apresentou regulares porcentagens de tubérculos com película sôlta.

\section{1 - EXPERIÊNCIA 275. ${ }^{a}$, EM SÃO MIGUEL ARCANJO}

Esta experiência foi instalada na propriedade do Sr. Tadao Murozaki, em solo podzólico vermelho-amarelo, variação Laras. O plantio foi efetuado em 29 de outubro de 1963 , e a colheita em 13 de fevereiro de 1964. As produções e as porcentagens de tubérculos graúdos, ou seja, conhecidos comercialmente como tamanhos "especial" e "primeira", constam do quadro 1.

A análise estatística para os resultados da produção mostrou diferenças altamente significativas entre as variedades. Para um coeficiente de variação de $13,7 \%$, a diferença mínima significativa entre as variedades, pelo teste Tukey, foi de $4,1 \mathrm{t} / \mathrm{ha}$.

As variedades Dalco, Engelum G 495, Emergo e Plat 52-9 formaram o grupo das mais produtivas. Realta enquadrou-se como a menos produtiva, e as demais constituiram o grupo intermediário.

O exame dos tubérculos colhidos mostrou a Plat 52-9 com $54 \%$ de seus tubérculos atacados de rizoctoniose.

\section{2 - EXPERIÊNCIA 276. a, EM MONTE ALEGRE DO SUL}

Iristalada na Estação Experimental do Instituto Agronômico, localizada em Monte Alegre do Sul, em solo podzólico vermelho-amarelo orto.

O plantio se deu em 11 de novembro de 1963, e a colheita $\epsilon \mathrm{m} 3$ de março de 1964. As produçōes e as porcentagens de tubérculos, graúdos estão contidas no quadro 1 .

A análise estatística, para os resultados da produção, mostrou diferenças significativas entre as variedades. A diferença mínima significativa entre as variedades, pelo teste de Tukey, foi de $3,7 \mathrm{t} / \mathrm{ha}$, e o coeficiente de variação foi de $7,2 \%$. 
QUAdRo 1. - Produções médias obtidas e porcentagens:

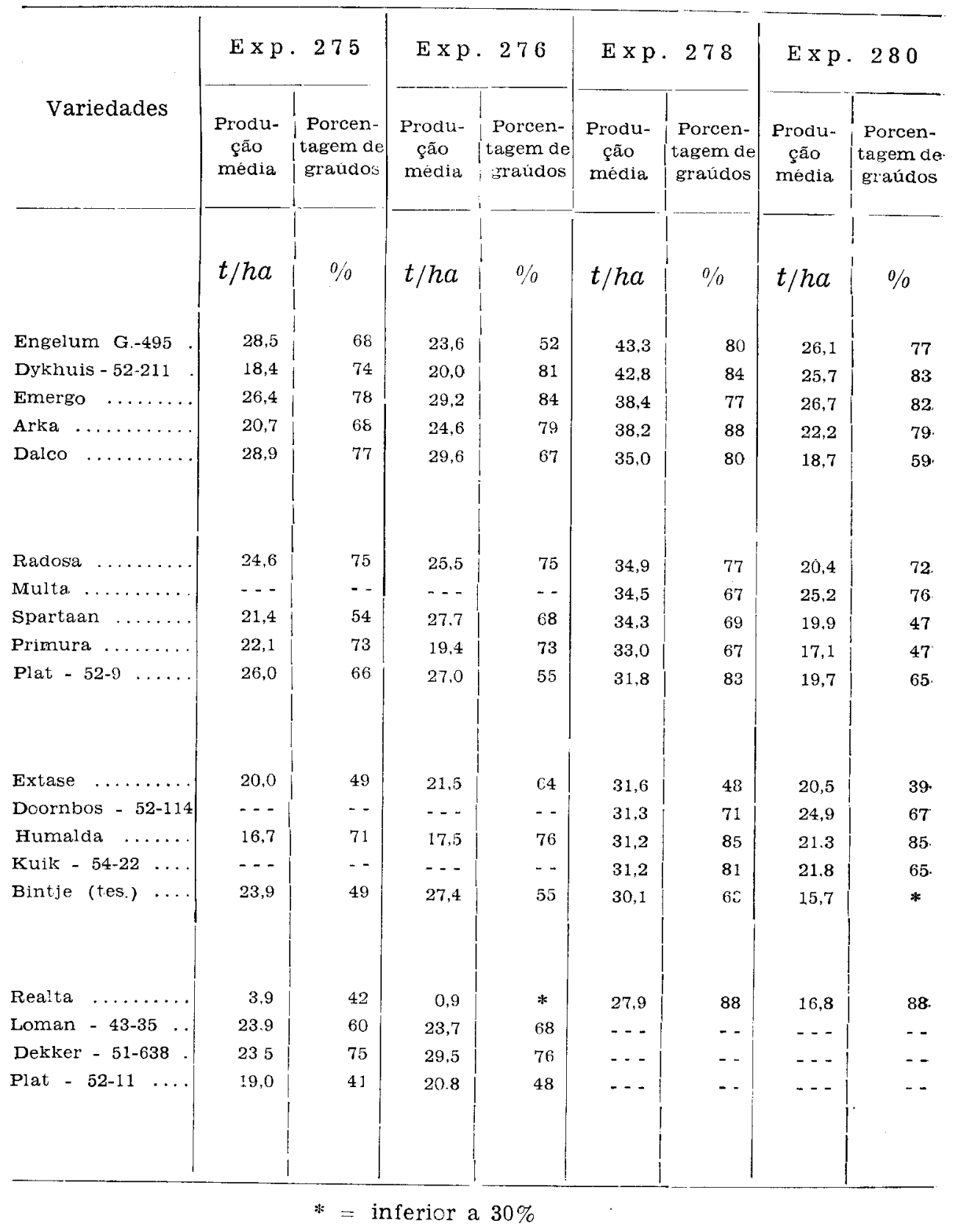


de tubérculos graúdos sôbre a produção total

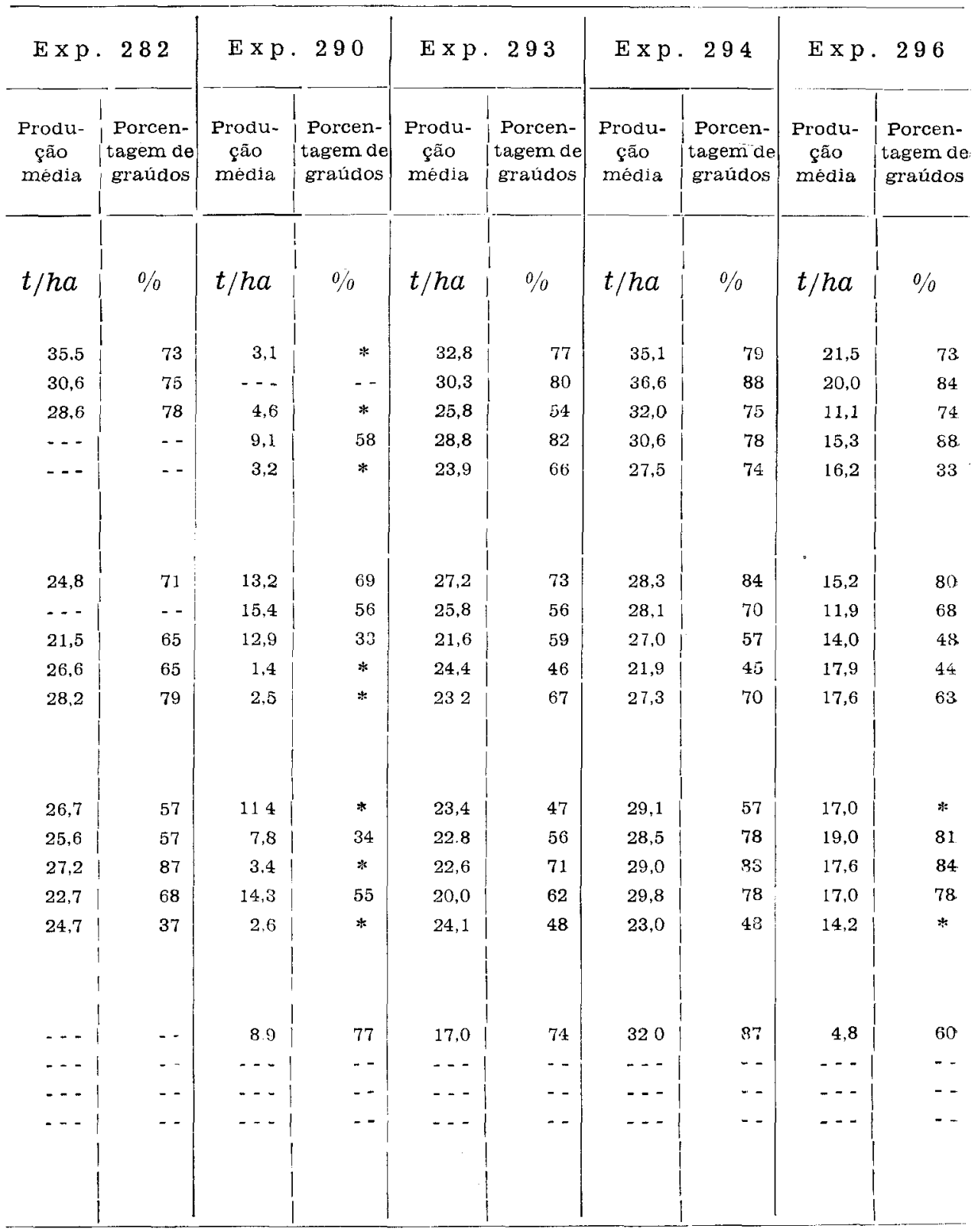


As variedades Dalco, Dekker 51-638, Emergo, Spartaan, Bintje (testemunha) e Plat 52-9 formaram o grupo das mais produtivas. Realta foi a menos produtiva. As restantes enquadraram-se no grupo intermediário.

O exame dos tubérculos colhidos mostrou a variedade Dalco com $52 \%$ de seus tubérculos com defeito de "embonecamento", e a Loman 43-35 apresentou grande incidência de manchas internas.

\section{3 - EXPERIÊNCIA 278. ${ }^{a}$, EM IBIÚNA}

O plantio foi realizado em 3 de março de 1964, na propriedade do Sr. Masao Takahashi, em solo podzolizado com cascalhos. A colheita se deu em julho cie 1964. As produções e as porcentagens de tubérculos graúdos constam do quadro 1. A análise estatística, para resultados de produção, mostrou diferenças altamente significativas entre as variedades. A diferença mínima significativa entre as variedades, pelo teste Tukey, foi de $7,8 \mathrm{t} / \mathrm{ha}$, e o coeficiente de variação foi de $10 \%$.

Engelum G 495, Dykhuis 52-211, Emergo e Arka formaram o grupo mais produtivo, enquanto que as restantes constituiram o grupo de produtividade menor.

O exame dos tubérculos colhidos mostrou Humalda com 28\% de sarna prateada.

\section{4 - EXPERIÊNCIA 280.a, EM PIEDADE}

Instalada em 16 de março de 1964, na propriedade do $\mathrm{Sr}$. Mário Tonarelli, em solo latosol vermelho-amarelo orto.

Nesta experiência houve uma generalizada ocorrência de requeima e pinta-preta. Bintje e Primura mostraram-se as mais sensiveis em relação a essas moléstias. Com exceção da Doornbos 52-114, Kuik 54-22, Multa, Engelum G 495 e Humalda, que apresentaram leve resistência, as restantes mostraram-se bem suscetíveis ao ataque de pinta-preta.

A colheita ocorreu em 8 de julho de 1964. As produções e porcentagens de tubérculos graúdos constam do quadro 1. A ariálise estatística, para os resultados da produção, mostrou ciferenças altamente significativas entre as variedades. A diferença mínima significativa foi de $15,3 \mathrm{t} / \mathrm{ha}$, e o coeficiente de variação fni de $11,2 \%$. 
Emergo, Engelum G 495, Dykhuis 52-211, Multa, Doornbos 52-114, Arka e Kuik 54-22 enquadraram-se como as mais produtivas. Humalda esteve no grupo intermediário, e as demais formaram o grupo menos, produtivo.

O exame dos tubérculos mostrou que as variedades Primura, Radosa e Spartaan apresentaram regulares porcentagens de seus tubérculos atacados pela sarna comum. Humalda e Spartaan apresentaram $30 \%$ de sarna prateada.

\section{5 - EXPERIÊNCIA 282.a, EM POMPÉIA}

O plantio se deu em 15 de abril de 1964, na propriedade do Sr. Kazuhisa Ninomyia, em solo podzolizado, variação Marília.

Foram excluídas desta experiência as variedades Multa, Arka, Dalco e Realta, por apresentarem brotações muito alongadas. Com estas foi feito um campo de observação ao lado da experiência.

Houve um prolongado período de estiagem. Com exceção das variedades Kuik 54-22, Engelum G 495 e Plat 52-9, as demais apresentaram sintomas de intensa falta de água, ou seja, tiveram suas hastes bem acamadas. A cultura do agricultor, ao lado desta experiência, estabelecida com a variedade Aquila, apresentou boa resistência à estiagem. As fôlhas desta variedade apresentavam-se túrgidas.

As variedades Primura, Humalda, Spartaan, Doornbos 52-114, Bintje e Emergo foram as mais precoces. Kuik 54-22, Plat 52-9, Extase e Radosa mostraram-se tardias, enquanto que Dykhuis 52-211 e Engelum G 495 foram meio precoces.

A colheita se deu em 7 de agôsto de 1964. As produções e porcentagens de tubérculos graúdos constam do quadro $1 . \quad$ A análise estatística, para os resultados da produção, revelou diferenças altamente significativas entre as variedades. A diferença mínima significativa foi de $7,2 \mathrm{t} / \mathrm{ha}$, e o coeficiente de variação foi de $12,2 \%$.

As variedades Engelum G 495, Dykhuis 52-211 e Emergo formaram o grupo mais produtivo. O exame dos tubérculos mostrou que as variedades, Engelum G 495, Plat 52-9, Spartaan, Radosa, Doornbos 52-114 e Multa apresentaram película de coloração acastanhada. As variedades Bintje, Spartaan, Radosa e Dalco mostraram película "cascuda" do meio para o ápice do 
tubérculo. Humalda apresentou $48 \%$ de podridão sêca na região basal ou do stolom do tubérculo. Multa apresentou 50\% de rizoctoniose grave. Dalco e Multa, com 30\% de sarna prateada. Com exceção das variedades Extase, Dykhuis 52-211 e Realta as demais apresentaram-se com película "cascuda". Excetuando-se as variedades, Extase, Dalco e Multa as demais apresentaram rnanchas internas, na região do stolom do tubérculo, um pouco semelhantes às manchas produzidas por geada.

Os tubérculos, armazenados em condições, normais de depósito de batata, apresentaram, com intensidades diferentes, brotoções afiladas,. Bintje, Emergo, Engelum G 495 e Dalco apresentaram a maioria de seus tubérculos com brotos afilados. As menores incidências dêsse afilamento ocorreram com as variedades Extase, Primura, Radosa, Doornbos 52-114 e Humalda.

\section{6 - EXPERIENNCIA 290.a, EMI PIEDADE}

Instalada em 9 de setembro de 1964, na propriedade do Sr. Mário Tonarelli, em solo latosol vermelho-amarelo variação orto.

A variedade Dykhuis 52-211 não constou desta experiência, pois, mesmo submetidos os seus tubérculos a "forçamento" de brotação com bissulfureto de carbono, na dosagem de 25 mililitros por metro cúbico de câmara, não teve suas gemas brotadas.

Condições favoráveis à invasão e disseminação do agente da requeima fizeram com que esta se manifestasse com grande ix.tensidade. De um certo modo as produçōes obtidas estão correlacionadas às tolerâncias das variedades àquela moléstia. As variedades Primura, Bintje, Plat 52-9, Humalda e Engelum G 495, apresentaram-se altamente suscetiveis à requeima.

O colheita foi efetuada em 21 de janeiro de 1965. As prođuções e porcentagens de tubérculos, graúdos constam do quadro 1. A análise estatística, em relação às produções, mostrou diferenças altamente significativas entre as variedades. A diferença minima significativa foi de $4,3 \mathrm{t} / \mathrm{ha}$, e o coeficiente de variação foi de $25,8 \%$.

Multa, Kuik 54-22, Radosa, Spartaan e Extase formaram o grupo mais produtivo. Arka, Realta e Doornbos 52-114, enquaäraram-se no grupo intermediário. As demais constituiram o grupo menos produtivo.

O exame dos tubérculos mostrou generalizada incidência de ataque de nematóides produtores de galhas. 


\section{7 - EXPERIÊNCIA 293. ${ }^{a}$, EM IBIÚNA}

Instalada em 18 de março de 1965, na propriedade do Sr. Masao Takahashi, em solo podzolizado com cascalhos.

O campo experimental sofreu as conseqüencias de uma forte geada, quando as plantas estavam com aproximadamente 60 dias de nascidas.

A colheita se deu no dia 5 de julho de 1965. As produções e porcentagens de tubérculos, graúdos constam do quadro 1 . A análise estatística dos dados de produção revelou diferenças altamente significativas entre as variedades. A diferença minima significativa foi de $7,1 \mathrm{t} / \mathrm{ha}$, e o coeficiente de variação foi de $11,1 \%$.

As variedades Engelum G 495, Dykhuis, 52-211, Arka, Radosa, Emergo e Multa formaram o grupo mais produtivo. Primura enquadrou-se no grupo intermediário, e as demais constituiram o grupo menos produtivo.

O exame dos tubérculos revelou que. com exceção da Bintje, houve generalizada incidência de sarna prateada. Humalda e Radosa apresentaram respectivamente $60 \%$ e $80 \%$ de sarna prateada de forma mais grave. Multa e Realta apresentaram 60\% de rizoctoniose. Spartaan mostrou-se com 100\% de lenticelose.

\section{8 - EXPERIÊNCIA 294.a, EM PIEDADE}

Instalada em 9 de março de 1965, na propriedade do Sr. Kazumi Hatatani, em solo latossol vermelho-amarelo, variação orto.

Primura, Plat 52-9, Dalco, Bintje, Engelum G 495, Emergo, Spartaan, Radosa, Doornbos, 52-114 e Extase apresentaram fraca tolerância ao agente da pinta preta.

A colheita foi efetuada em 28 de junho de 1965 . As produçōes e porcentagens de tubérculos graúdos constam do quadro 1 . A análise estatística dos resultados de produção revelou diferença mínima significativa de $7,1 \mathrm{t} / \mathrm{ha}$, e coeficiente de variação foi de $9,5 \%$.

Dykhuis, 52-211, Engelum G 495, Emergo, Realta, Arka e Kuik 54-22 formaram o grupo mais produtivo. Extase constituiu o grupo intermediário. As demais estiveram no grupo menos produtivo. 
O exame dos tubérculos apontou a variedade Radosa com $80 \%$ dêles com sarna comum. A variedade Dalco apresentou $90 \%$ de tubérculos com película "cascuda" do meio para o ápice.

\section{9 - EXPERIÊNCIA 296. ${ }^{\mathrm{a}}$, EM POMPÉIA}

Instalada em 6 de abril de 1965, na Fazenda Cedral, de propriedade dos Irmãos Hojo, em solo podzolizado variação Marília.

A colheita foi efetuada em 10 de agôsto de 1965. As produçōes e as porcentagens de tubérculos graúdos constam do quadro 1. A análise estatística mostrou diferenças altamențe significativas entre as variedades. A diferença mínima significativa foi de $7,4 \mathrm{t} / \mathrm{ha}$, e o coeficiente de variaçāo de $20,7 \%$.

Engelum G 495 apresentou 80\% das plantas com enrolamento de fôlhas.

Engelum G 495, Dkyhuis 52-211, Doornbos 52-114, Primura, Humalda, Plat 52-9, Kuik 54-22, Extase, Dalco, Arka, Radosa e Bintje formaram o grupo mais produtivo. Spartaan apresentou produção intermediária. Multa, Emergo e Realta apareceram no grupo menos produtivo.

Do exame dos tubérculos colhidos notou-se uma generalizada incidência de sarna prateada. As maiores porcentagens dêsse ataque couberam às variedades Multa, Radoșa, Humalda, Plat 52-9, Emergo, Engelum G 495 e Arka. Houve também generalizado ataque de nematóides produtores de galhas. As variedades Dalco, Extase e Emergo tiveram seus tubérculos com porcentagens acima de 50\% dêsse ataque; a menor porcentagem $(12 \%)$ coube à variedade Realta.

De modo geral, a película dos tubérculos apresentou-se "cascuda". As variedades Dykhuis 52-211, Engelum G 495, Kuik 54-22, Emergo, Plat 52-9, Spartaan, Doornbos 52-114, Arka, Dalco e Realta apresentaram-se com $50 \%$ a $80 \%$ dêsse defeito. A menor porcentagem $(6 \%)$ coube à variedade Humalda.

\section{4 - CONCLUSÕES}

Dos resultados das nove experiências levadas a efeito em diferentes tipos de solo e clima do Estado de São Paulo, nas quais procurou-se verificar o comportamento de quinze novas variedades de batatinha de origem holandesa, pôde-se tirar as seguintes conclusões: 
a) As variedades Engelum G 495 e Dykhuis 52-211 foram as mais produtivas sob condiçōes de solo arenoso e plantio de outono (março-abril).

b) As variedades Engelum G 495, Dykhuis 52-211, Emergo, Arka e Multa foram as mais produtivas quando plantadas em solos argilo-arenosos e na época "da sêca” (janeiro-fevereiro).

c) As variedades Dalco, Emergo, Plat 52-9 e Engelum G 495 mostraram-se mais produtivas quando plantadas em solos argilo-arenosos e na época "das águas” (outubro-novembro).

d) As variedades Dykhuis 52-211, Humalda, Engelum G 495, E'mergo, Arka, Realta e Radosa apresentaram as maiores porcentagens de tubérculos graúdos.

e) Nenhuma das variedades apresentou resistência ou boa tolerância aos agentes das moléstias requeima e pinta preta. As variedades menos suscetiveis dentre as testadas foram a Kuik 54-22 e Realta.

f) Os melhores aspectos de tubérculo foram dados pelas variedades Primura, Bintje e Dykhuis 52-211.

\section{COMPETITION OF DUTCH POTATO VARIETIES}

\section{SUMMARY}

This paper presents the results of nine trials located in five potato producing areas in the State of São Paulo, Brazil, whose purpose was to study the behavior of fifteen Dutch potato varieties.

Engelum G 495, Dykhuis 52-211, Emergo, Arka, Multa Kuik 54-22, Radosa, Spartaan and Extase had the best yields.

The varieties Dykhuis 52-211, Humalda, Engelum G 495, Emergo, Arka, Realta and Radosa showed the largest percentages of long-size tubers, while Primura, Bintje and Dykhuis 52-211 proved to have the best looking tubers. 